\title{
O MONSTRO DE SER QUEM SE É: \\ O DUPLO NO CONTO “MIMOSA PUDICA”, DE CEZAR TRIDAPALLI
}

\author{
João Claudio Arendt* \\ Natalia Susin Cechinato ${ }^{* *}$
}

RESUMO: O presente artigo objetiva contribuir para os estudos sobre o duplo na literatura e, para tal, analisa, com base nos estudos de Otto Rank (1939) e Clément Rosset (1998), tanto as formas de representação do duplo encontradas no conto "Mimosa pudica" (2014), do autor curitibano Cezar Tridapalli, como os processos de personificação e aceitação por parte do protagonista. Na narrativa de Tridapalli, o duplo é representado por monstros que povoam a mente turbulenta do personagemnarrador e se manifesta durante agudas crises de enxaqueca. O conflito existencial do protagonista emerge da desgastada relação com a esposa, sobre quem repousa a desconfiança de adultério.

PALAVRAS-CHAVE: Duplo; "Mimosa pudica"; Monstros imaginários.

\footnotetext{
* Doutorado em Lingüística e Letras pela Pontifícia Universidade Católica do Rio Grande do Sul (Puc-RS). Professor Adjunto II da Universidade de Caxias do Sul (UCS).

** Mestranda do Programa de Pós-Graduação em Letras daUniversidade de Caxias do Sul (UCS).
} 


\section{Introdução}

Continuei, a tal ponto que o menor gesto me afligia, a mais ínfima palavra, uma insistência qualquer; muita vez só a indiferença bastava.

Cheguei a ter ciúmes de tudo e de todos. Um vizinho, um par de valsa, qualquer homem, moço ou maduro, me enchia de terror ou desconfiança.

(Dom Casmurro, Machado de Assis)

A infelicidade deu um pulo medonho: notei que Madalena namorava os caboclos da lavoura. Os caboclos, sim senhor. [...] Os meus olhos me enganavam. Mas se os olhos me enganavam, em que me havia de fiar então? (São Bernardo, Graciliano Ramos)

O presente artigo propõe-se a analisar a representação do duplo no conto "Mimosa pudica", de Cezar Tridapalli. Nascido em Curitiba em 1974, o autor publicou Pequena biografia de desejos (2011) e foi vencedor do Prêmio Governo de Minas Gerais de Literatura, com o romance O beijo de Schiller (2012). Tridapalli, por algum tempo, foi colunista do site Gą̧eta do Povo, na seção intitulada "Educação e Mídia", e atuou como professor em algumas instituições de ensino localizadas na capital paranaense.

A versão do conto "Mimosa pudica" tomado para análise está publicado na coletânea 48 contos paranaenses, lançado em 2014. Organizado por Luiz Rufatto ${ }^{1}$, a antologia tem como propósito reunir produções de autores do Paraná, as quais, porém, não mostrassem ligação direta com temas regionais ou regionalistas. De um modo geral, a antologia dedicase a construir um painel da produção contística paranaense dos séculos XX e XXI, reunindo escritores de diferentes visibilidades naquele estado e no Brasil.

O conto "Mimosa pudica" é narrado em primeira pessoa por um homem que há muito está apaixonado por uma mulher que não corresponde a esse sentimento da maneira como ele deseja. Durante uma aguda crise de enxaqueca, a personagem começa a se questionar sobre o passado e a enxergar suas indagações em forma de monstros que ocupam a casa e, inclusive, interagem entre si e com ele.

${ }^{1}$ Escritor vencedor do Prêmio Machado de Assis e ganhador do Troféu APCA, concedido pela Associação Paulista de Críticos de Arte, ambos pela obra Eles eram muitos cavalos, de 2001. 
O narrador-personagem, ao mesmo tempo em que deseja fugir da companhia dos monstros, sente-se seguro por tê-los perto de si como protetores, principalmente quando o mundo real torna-se difícil de suportar. Nesse contexto narrativo, é possível afirmar que o desafio maior para o protagonista reside na sua incapacidade ou falta de vontade para resolver o impasse amoroso com a mulher amada.

\section{O duplo representado por monstros}

No conto de Cezar Tridapalli, o duplo emerge representado por monstros imaginários que povoam a casa escura da personagem, e o que primeiro chama a atenção é o gatilho que torna esses seres visíveis:

Foi por causa da enxaqueca que aprendi a flertar com a escuridão. O escuro não permite que sejamos distraídos pelos olhos. Ou traídos pelos olhos, num trocadilho fácil. O que surge do escuro são imagens que não brotam de outro lugar que não seja uma cabeça momentaneamente sem janelas (TRIDAPALLI, 2014, p. 75).

Para a personagem, a enxaqueca, que o obriga a ficar no escuro, seria responsável por desencadear toda uma rede de pensamentos e questionamentos a respeito de si e da sua vida, os quais, à luz do dia ou no cotidiano ordinário, não poderiam ser reconhecidos. Por outro lado, é possível que tais indagações e percepções não seriam visíveis simplesmente por escolha da própria personagem. É o que sugere Otto Rank (1939, p. 8), ao afirmar que a representação do duplo está ligada ao “domínio da vida interior”.

Se a personagem do conto não consegue ou não pode lidar com suas incertezas, é provável que esse seja um dos motivos que o levam a manter contato com os monstros. Ao nos aproximarmos mais do estudo de Rank (1939), percebemos que há pelo menos duas representações do duplo no conto em questão. Por um lado, o duplo só é visível para quem está, de certa forma, com algum desafio posto em relação à própria subjetividade, ou seja, nesse caso a personagem está claramente em conflito consigo mesma, com sua história passada e futura: 
Eles chegaram tateando (o tato não é inimigo da enxaqueca) o ambiente obscuro, bateram a canela nos móveis, gritaram de dor, riram da situação inusitada, ai, bati meu dedo, o que é isso aqui no meio da sala? E se instalaram. O que resta a alguém privado dos sentidos são esses seres de memória e imaginação. Uma aponta para trás e a outra pode apontar para frente, uma frente feita de inexistências e um atrás feito de pedaços emendados por costureiros infiéis (TRIDAPALLI, 2014, p. 75).

De acordo com Rank (1939, p. 14), “o passado de um indivíduo está ligado tão intimamente à sua existência, que se tornará desgraçado tentar desligar-se dele". É em razão disso, talvez, que o protagonista mostra-se incapaz de se orgulhar do passado, ou esperar por algo bom do seu futuro. Ainda com base no excerto do conto anteriormente transcrito, constatamos que o homem parece representar alguém que acredita que um passado obscuro pode condenar o futuro. Por outro lado, do ponto de vista da segunda representação do duplo no conto, existe a possibilidade de o protagonista representar alguém que não ama a si mesmo e, por isso, torna-se inapto para expressar o seu afeto à mulher.

Essas duas perspectivas do duplo presentes no conto trazem à tona a insatisfação da personagem consigo mesma e com Ana, a mulher a quem devota o seu amor desde a juventude:

Minhas esperanças eram burras. Eu queria que minhas mãos ásperas alisassem o comportamento áspero de Ana. Asperezas com asperezas fazem nascer o improvável, eu pensava: lixa na parede arisca origina lisuras insuspeitadas (a lixa se desgasta, a parede se alisa). Esse era meu raciocínio e também minha esperança (TRIDAPALLI, 2014, p. 76).

Para o narrador-personagem, há uma mescla de amor e contrariedade, porque ele sente que não foi correspondido em nenhum momento da relação que já dura mais de uma década. A enxaqueca, nesse caso, pode ter surgido como um mecanismo de fuga, já que, quando a vida do casal parece engrenar, inclusive com o nascimento do filho, o homem continua buscando a atenção que acredita nunca ter recebido de Ana. 
Considerando-se não só que a personagem narra os fatos no presente, com um regresso até o momento em que o casal se conhece, mas, também, a sua desconfiança a respeito da infidelidade da própria memória, é provável que haja uma distorção não deliberada dos acontecimentos. Nesse sentido, é a figura de Ana que causa o maior embate interno da personagem e a faz mover-se na trama:

Fomos morar juntos uma semana depois de meu aniversário de quarenta anos. Fiquei quinze anos apaixonado por Ana até ela resolver morar comigo. Depois, continuei apaixonado. Ela não. Nunca foi, nem antes nem depois. Não houve magnetismo. Fui seu ímã, ela apenas parede fria. E áspera. Eu tentava me agarrar, mas caía o tempo todo (TRIDAPALLI, 2014, p. 76)

Nessa passagem, percebe-se a "cegueira voluntária”, proposta por Rosset (1998), como o artifício que o ser humano encontra para fugir do real. Em "Mimosa pudica", a cegueira evidencia-se no fato de a personagem admitir a frieza da esposa e, mesmo assim, continuar a insistir na relação, como ímã em parede fria, no dizer do narrador.

Ainda no que diz respeito à recusa do real, é pertinente o que Rosset (1998) afirma:

Se o real me incomoda e se desejo livrar-me dele, me desembaraçarei de uma maneira geralmente mais flexível, graças a um modo de recepção do olhar que se situa a meio-caminho entre a admissão e a expulsão pura e simples: que não diz sim nem não à coisa percebida, ou melhor, diz a ela ao mesmo tempo sim e não (ROSSET, 1998, p. 13).

Há no comportamento da personagem do conto uma certa complacência, pois, apesar de ser recusado pela amada, o homem continuou a agir de modo a crer que qualquer gesto por parte dela fosse uma manifestação de carinho. É o que se observa em outro trecho do conto: "Ana acreditou no cisco e quase se ofereceu para soprar meus olhos. Senti mesmo que ela quase se ofereceu. Eu lia o quase como uma manifestação de carinho dela e isso me bastava para ser feliz" (TRIDAPALLI, 2014, p. 77). 
Na perspectiva de Rosset (1998), é possível asseverarmos que, uma vez que a personagem está cegada pelo sentimento transposto para o seu duplo, ou o duplo é desencadeado por uma terceira personagem (geralmente uma mulher), torna-se inútil mostrar a realidade ao indivíduo, porque ele está iludido. O filósofo ainda sugere que o sujeito iludido presta atenção somente aos fantasmas de sua imaginação e de seu desejo e, então, criam-se as condições ideais para que o duplo se manifeste.

\section{A aceitação do duplo}

Se a personagem do conto em análise recusa o real, ela está, consequentemente, aceitando o mundo da sua própria imaginação. Esse aspecto pode ser observado em outros textos da literatura ocidental, como, por exemplo, no conto "O Sul”, de Borges, quando Dahlmann dá-se conta de algumas estranhezas no que se refere ao tempo transcorrido, mas decide ignorar esse fato, seguindo sua aventura em busca de uma morte digna para um gaúcho. ${ }^{2}$ A passagem a seguir ilustra esse aspecto: “[...] era como se a um tempo fosse dois homens: o que avançava pelo dia outonal e pela geografia da pátria, e o outro, enclausurado numa clínica e dependente de metódicas criadagens" (BORGES, 1999, p.587).

A personagem criada por Borges defronta-se com seu maior medo: o de morrer como um velho doente e não como um herói, tal qual o seu avô que fora um combatente de guerra. Pela ótica de Rosset (1998, p. 11), “o real só é admitido sob certas condições e apenas até um certo ponto: se ele abusa e mostra-se desagradável, a tolerância é suspensa". No caso de Dahlmann, é possível observarmos o esforço da personagem para que a própria morte atenda a um padrão por ela exigido, além do rechaço da realidade em si. O mesmo ocorre com a personagem de Tridapalli, a qual nutre uma imagem de perfeição sobre as próprias atitudes que não a levam a um resultado planejado e, assim, entra em conflito com a mulher por julgar que foram as atitudes dela que o levaram à crise e ao fracasso social.

\footnotetext{
2 O gaúcho é símbolo cultural argentino, representado pela figura de um pastor que vivia nos pampas e lidava com o gado. Geralmente, ele remete à bravura e à masculinidade.
} 
A partir da insatisfação com o real desagradável, Dahlmann recusa-se a enxergar a situação em que vive e é tomado por uma autoilusão, mergulhando em um estado de cegueira, até que, ao final da narrativa, entra em confronto com alguns homens em um bar. O narrador não deixa claro se Dahlmann morreu em um leito da clínica em que supostamente foi internado, ou se sua morte aconteceu de fato no confronto com os dois gaúchos. Essa forma de conclusão do conto leva-nos à ideia de Rosset (1998), que acredita que a estrutura fundamental do real está contida na sua unicidade e singularidade, mas tal percepção pode desencadear duas linhas de pensamento: por um lado, a raridade de ser quem se é e, por outro, a clareza de que a existência termina.

Ainda de acordo com Rosset (1998), a técnica utilizada por um ilusionista é a mesma que o "cego voluntário" utiliza para que sua fuga torne-se aceitável, nem que seja apenas para si mesmo. O iludido desloca e duplica, ou seja, ele dirige o olhar para outro lado, onde não acontece nada, ou, no caso da personagem do conto "Mimosa pudica", para o lado onde encontra certo conforto. É o que se observa na passagem a seguir:

Não ser apaixonado é condição básica para ser apaixonante. Isso é o que dizem esses seres que habitam meu escuro. Que eu chamo de monstros, repito, sem saber bem por quê. Parecem ter se acostumado à escuridão e já não esbarram nas coisas com tanta frequência. Conversam de modo confortável, acendem cigarros, tomam café, dão suas risadas (TRIDAPALLI, 2014, p. 77).

O protagonista aceita seu duplo, porque o teme e, apesar de, em algumas passagens, parecer louco e não entender o que se passa consigo, ele deixa claro que não há maneira de apagar o passado ou de prever o futuro. Os "fantasmas" que o perturbam são insistentes, até o ponto em que outro homem surge para quebrar a linearidade das atitudes da personagem. Esse homem, que antes parecia inerte, mostra-se incomodado e compara-se a todo momento com o concorrente que despertou a paixão de Ana em um passeio pela praia. A essa altura da narrativa, notamos a atenção da personagem voltada exageradamente para si mesma. Esse aspecto, segundo Rank (1939), diz respeito não somente à incompetência para amar outra pessoa (segundo o autor, um dos motivos para a frequente representação do 
duplo nas artes), mas também a uma forte tendência ao narcisismo ${ }^{3}$. No conto, a situação coaduna-se à insegurança da personagem:

Ana, dê licença, deixa eu olhar o homem sentado no banco, me deixa observá-lo longamente, ver detalhes, os cabelos grossos e lisos, como o nariz se encaixa no rosto, qual o desenho da boca, se as orelhas são simétricas, a barba sem redemoinhos, de que modo o pescoço sustenta a cabeça, como o ar vibra nas cordas vocais, se trejeitos com as sobrancelhas [...] (TRIDAPALLI, 2014, p. 78).

Para Rank (1939, p. 126), “o duplo é o arquétipo de seu rival em tudo, mas principalmente na questão amorosa". Então, se considerarmos que o protagonista vê o "homem que via o mar" como uma ameaça e procura nele o que falta em si, é possível que as atitudes dos monstros divisados por ele sejam um desdobramento do seu duplo.

Ao passo que o narrador está curioso a respeito do novo amor de Ana, percebe-se uma necessidade de ele projetar-se no outro, dando ainda mais força ao seu duplo. Quando Ana engravida, o protagonista, em vez de passar a sujeito de si, continua a manter contato com as criaturas fictícias, transferindo o real para o seu duplo imaginado.

\section{A personificação do duplo}

A partir do momento em que Ana engravida, o narrador desaba em um conflito ainda maior, principalmente porque, com a chegada da criança, a esposa também entra em depressão e vai se apagando lentamente para a existência. Nesse processo de narrar sua experiência, o que mais chama a atenção no protagonista é que ele observa a morte lenta da mulher e parece conformar-se com isso, mostrando-se preocupado apenas com sua própria situação. O excerto a seguir confirma essa percepção:

\footnotetext{
${ }^{3} \mathrm{O}$ termo narcisismo tem sua origem no clássico mito grego de Narciso, um jovem belo confinado pelos deuses a nunca conhecer a si mesmo e condenado a um amor impossível de consumar. Despertava o amor das jovens gregas e das ninfas, mas era arrogante e as desprezava. Um dia, Narciso aproximou-se de um lago e se apaixonou pela sua própria imagem refletida na água, lançando-se ao lago para se unir àquele por quem se apaixonara - ele próprio.
} 
Demos até de falar sozinhos. Eu era atacado por crises de enxaqueca e me entocava no quarto escuro. Ana não se mexia muito, dava um pequeno espaço na cama e permanecia lá, a barriga crescendo, ela diminuindo. Lado a lado, ouvia seus sussurros consigo mesma enquanto eu ruminava minhas próprias incompreensões (TRIDAPALLI, 2014, p. 79).

Nesse processo de afastamento do casal, Ana morre, e ao homem resta a tarefa de tomar conta do filho, que acredita não ser seu. Esse fato intensifica o sentimento de insegurança da personagem, que observa o bebê ao seu lado e busca nele forças para seguir em frente. Todavia, para narrar a morte da esposa, a personagem passa a utilizar um certo lirismo, como se, por meio desse recurso, fruto do seu duplo, pudesse justificar-se:

É que o caos tem seus métodos. Ele desarruma e propõe na desordem. Mas não sei ler desordens. Se estou aqui junto ao menino e ao ser imenso - que me encobre com as mãos em concha - cerzindo um passado aos pedaços mergulhado na infidelidade da memória, à frente tenho um futuro inexistente, página em branco prometendo um devir escuro. A imaginação não consegue projetar. Um dos monstros talvez tenha cochilado, não me sugere nada, não me dá pistas sobre que caminhos preciso desenhar no compasso do tempo. (TRIDAPALLI, 2014, p. 81)

Ao passo que a personagem exprime seu sofrimento por meio de uma linguagem mais poética, ela também manifesta uma tentativa de explicação para o fato de estar visualizando seus medos de maneira concreta, posto que ela assume estar passando por uma fase caótica e praticamente coloca a responsabilidade das suas frustrações (entre elas, a morte da mulher) sobre as tais criaturas imaginárias.

Para Lamas (2004), o duplo não é um recurso narrativo apenas do conto fantástico. Ele também é utilizado na literatura em geral para exprimir certas angústias do ser humano em sua vida ordinária:

A jornada do ser humano pela vida é pautada pela aguda consciência das angústias e principalmente da dicotomização - matéria e espírito - do homem contemporâneo, já que um dos maiores problemas do homem moderno é a fragmentação acentuada na entrada do terceiro 
milênio. E, por conseguinte, as dificuldades que se apresentam para realizar o potencial de cada um (LAMAS, 2014, p. 44)

Nesse sentido, a personagem do conto é tomada por um sentimento quase pueril, desejando regredir à idade do menino que tem nos braços, para poder sentir-se acolhido e seguro novamente. É assim que surge mais uma fase para o duplo no conto: o homem projeta sua imagem na criança e a transforma em um monstro que assume o papel de protegê-lo:

Quanto ele mede? Três metros, três metros e meio? Quatro? Meus pés sentem a palma da mão enorme envolvendo-os e apertando-os com força e carinho. Essa mão gigantesca e vigorosa sobe pelo meu corpo, me arrepia, passa por entre as coxas, bate de leve e acaricia minha bunda [...]. A mão gigante não é predadora, mas seu toque me encolhe. Mais trocadilhos fáceis: me escolhe, colhe, recolhe, me acolhe. Meu corpo, a planta dormideira, a mimosa pudica (TRIDAPALLI, 2014, p. 81)

Nesse excerto, percebe-se a referência ao duplo pelo fato de o homem narrar o seu desejo de se sentir acolhido, no momento em que ele próprio está acolhendo a criança com o seu corpo. Ele imagina-se sob a proteção do grande monstro, ao mesmo tempo que assume uma posição de protetor da criança:

A enxaqueca não é inimiga do tato, repito. Sinto o menino aqui comigo, deitado de lado, ressonando já há mais de uma hora. Sua cabeça está aninhada na minha axila esquerda, meu braço e tórax servindo de guarida. [...] Estampa-se então na câmara escura um ser imenso a me acocar na sua axila esquerda, circum-navegando-me. Quanto ele mede? Três metros, três metros e meio? Quatro? Meus pés sentem a palma de uma mão enorme envolvendo-os e apertando-os com força e carinho. (TRIDAPALLI, 2014, p.80)

Em relação ao duplo como projeção, Rank (1939) afirma que ele não precisa necessariamente ser o gêmeo, ou a imagem refletida da personagem. Para que assim seja considerado, basta que ele possua vida própria, como acontece no conto de Tridapalli, em 
que as sensações da personagem passam a impressão de que o monstro encontra-se no mesmo espaço do quarto, confirmando a autonomia do duplo.

O texto de Tridapalli também possibilita uma aproximação com o conto "O espelho", de Guimarães Rosa, no qual o narrador, por mais que esteja discorrendo sobre sua imagem refletida, acredita que o espelho pode distorcer o real, se ele for de outro formato que não o plano. Além disso, até mesmo a semelhança mostrada pelo espelho tradicional pode provocar o desejo de fuga:

Vejo que começa a descontar um pouco de sua inicial desconfiança, quanto ao meu são juízo. Fiquemos, porém, no terra-a-terra. Rimonos, nas barracas de diversões, daqueles caricatos espelhos, que nos reduzem a monstrengos, esticados ou globosos. Mas, se só usamos os planos - e nas curvas de um bule tem-se sofrível espelho convexo, e numa colher brunida um côncavo razoável - deve-se a que primeiro a humanidade mirou-se nas superfícies de água quieta, lagoas, lameiros, fontes, delas aprendendo a fazer tais utensílios de metal ou cristal. Tirésias, contudo, já havia predito ao belo Narciso que ele viveria apenas enquanto a si mesmo não se visse... Sim, são para se ter medo, os espelhos (ROSA, 1988, p.121)

A aparição do grande monstro no texto de Tridapalli (2014) pode indicar, quando em comparação com o conto de Guimarães Rosa (1988), nada mais que o medo e o desgosto de ser quem se é. Tanto que o narrador de "O espelho" tem diversos questionamentos relativos a si mesmo e, a partir deles, imagina diferentes imagens suas como que refletidas em um espelho.

Kristeva (1994, p. 9) afirma que "o estrangeiro habita em nós: ele é face oculta da nossa identidade”. Nesse sentido, a personagem de Rosa (1988), ao encarar-se no espelho, está reconhecendo uma outra parte de si, antes obscurecida, ou uma identidade que não está em conformidade com o real. Da mesma forma, o auto-estranhamento - nesse caso, a recusa da própria realidade - torna-se o motivo para que o duplo no conto de Rosa (1988) surja com formatos distorcidos diante do espelho, já que a personagem está em um conflito com sua própria identidade. Ainda segundo Kristeva (1994), as estranhezas dos indivíduos são os seus próprios abismos e incoerências, ou seja, se a representação do 
duplo no conto não é a imagem fiel da personagem no espelho, então são seus próprios questionamentos que a fazem saltar para fora de si, ou projetar-se deformadamente.

Outro aspecto que pode ser observado a partir do último fragmento transcrito do conto "O espelho" é o medo gerado pela negação do real. No estudo de Rank (1939) a respeito do desdobramento de personalidade, o autor relaciona-o ao medo da finitude da vida, em que o duplo seria uma tentativa da personagem de perdurar através do tempo e, como ela tem consciência de que isso é impossível, acaba transferindo-se a uma segunda representação do seu próprio eu. Esse aspecto aparece no conto de Rosa (1988) em cada uma das formas refletidas no espelho, visto que todas elas não condizem com a imagem fiel da personagem e, muitas vezes, despontam não somente em figuras deturpadas, mas descritas como maiores do que o tamanho físico da personagem, como, por exemplo, quando ela fala dos traços que recordam “o grande felino”. Nessa perspectiva, a personagem estende-se para o espelho, assumindo a figura de uma onça e tentando dissociar sua imagem da do animal.

Pela simples recusa da autoimagem, ou da recusa do real, o personagem-narrador de "Mimosa pudica" imagina monstros que são representações dos seus maiores medos (passado e futuro). Em seguida, quando seria de bom alvitre tomar a posição de protetor, acolhedor, responsável pela criança órfã de mãe, o homem, novamente, coloca-se em lugar vulnerável, no aconchego do abraço de um dos monstros.

Do ponto de vista do significado do título do conto em análise, a planta mimosa pudica ${ }^{4}$ pode simbolizar, conforme Chevalier (1994, p. 841), a energia vinda do sol, que, acumulada no interior das plantas, tem efeitos curativos ou venenosos. Poderia também simbolizar a vida e o crescimento do homem, ou, ainda, na tradição Védica, fazer parte das plantas consideradas divindades, por suas propriedades medicinais que seriam "presentes do céu”.

\footnotetext{
${ }^{4}$ A espécie Mimosa pudica é originária das Américas Central e do Sul. No Brasil, é conhecida pelo nome de nãome-toques ou dormideira. Quando tocadas, suas folhas fecham-se rapidamente, uma estratégia natural de defesa contra predadores.
} 
Todavia, no conto, porque o narrador mendigava a atenção da esposa e sofria com questões de autoestima, é possível que essa espécie de planta, em especial, tenha sido a maneira encontrada pelo autor para representar a carência afetiva da personagem que, a certa altura, afirma que o "encolhimento não é fuga, é aconchego de feto em útero" (TRIDAPALLI, 2014, p. 81).

A forma pela qual o protagonista transfere seus medos para o monstro que o acolhe parece atenuar o sofrimento após a suposta traição e morte da esposa, até que ele consiga entender o que de fato se passou. A personagem entra em um monólogo interior que a leva a concluir que o passado (um de seus monstros) não pode ser refeito, nem o futuro (outro monstro) pode ser projetado.

Voltando ao gatilho, percebe-se que, para que a personagem mantenha contato com esses seres da imaginação, ela precisa admitir que só é possível interagir com eles quando está com os sentidos atordoados pela enxaqueca:

Rirei dessa imagem criada durante o tempo em que os sentidos ficaram desmaiados. Onde já se viu? O que o torpor é capaz de produzir, conversarão os sentidos entre si, de volta ao controle. A culpa é da enxaqueca, dirão eles enquanto, abismados, expulsam os seres que haviam tomado posse da sala escura (TRIDAPALLI, 2014, p. 82)

Por fim, a personagem admite que todos os seres com os quais conviveu eram não mais que frutos da sua imaginação confusa, atordoada pelas crises de dor de cabeça. Ou, se voltarmos ao pensamento de Rank (1939), trata-se de "uma fuga do real", nesse caso desencadeada pela enxaqueca, mas ainda assim provocada pelo próprio sujeito. O protagonista sabe, ao final de tudo, que existe um abalo causado pelo real, mas "a vida entrará pelas nossas portas", ou seja, ele terá que procurar, finalmente, a felicidade na vida real.

\section{Considerações finais}

A análise do conto possibilita inferir, em última instância, que o duplo emerge na vida do narrador-personagem no contexto de uma crise de enxaqueca, que coincide com 
um momento de grave conflito existencial. O casamento frustrado em razão das diferenças entre o casal, a suspeita de adultério e o lento definhar de Ana são fulcrais para a manifestação do duplo. Assim, a percepção estratificada da realidade por parte do protagonista leva-o a uma espécie de metamorfose interna, ou seja, a uma duplicação ou cisão psicológica que é responsável pelo confronto com o seu próprio duplo: nesse caso, os monstros que habitam a escuridão do quarto.

Para além da análise aqui efetuada, o conto de Tridapalli remete aos dois romances citados na epígrafe deste trabalho: Dom casmurro (1899), de Machado de Assis, e São Bernardo (1934), de Graciliano Ramos. Em ambas as obras, há um narrador-protagonista que mergulha em uma crise existencial em razão da suspeita de adultério por parte da esposa, do que teria resultado um filho bastardo. A questão que se coloca é se, nessas narrativas, a questão do duplo não emerge na mesma perspectiva do conto de Tridapalli: a crise que leva os narradores a mergulharem em um conflito interno, de onde estratificam a realidade e se confrontam tanto com as esposas, os filhos, os supostos amantes, quanto consigo mesmos. Afinal, como já se afirmou anteriormente, na perspectiva de Rank (1939, p. 126), o duplo constitui o arquétipo do rival em diferentes situações, mas acentua-se principalmente na questão amorosa.

THE MONSTER OF BEING WHO YOU ARE: THE DOUBLE IN THE SHORT STORY "MIMOSA PUDICA", CEZAR TRIDAPALLI

ABSTRACT: The present paper aims to contribute to the studies about the double in the literature. It analyzes, based on the studies of Otto Rank and Clément Rosset, the forms of representation of the double found in the short story "Mimosa pudica", written by Cezar Tridapalli, and their processes of acceptance and embodiment. In Tridapalli's narrative, the double is represented by monsters that populate the turbulent mind of the main character and manifests itself during a migraine attack. The existential conflict of the protagonist emerges from the worn relationship with his wife, on whom rests the distrust of adultery.

KEYWORDS: "Mimosa pudica"; Imaginary monsters; Double. 


\section{REFERÊNCIAS}

BORGES, Jorge Luis. O Sul. In . Fiç̧ões: Obras Completas. São Paulo: Globo, 1999.

CHEVALIER, Jean et al. Dicionário dos simbolos: mitos, sonhos, costumes, gestos, formas, figuras, cores, números. 1994.

KRISTEVA, Julia. Estrangeiros para nós mesmos. Rio de Janeiro: Rocco, 1994.

LAMAS, Berenice Sica. O duplo em Lygia Fagundes Telles: um estudo em Literatura e Psicologia. Porto Alegre: Edipucrs, 2004.

MELLO, Ana Maria Lisboa de. As faces do duplo na literatura. Discurso, memória, identidade. Porto Alegre: Sagra Luzzato, 2000.

RANK, Otto. O duplo. São Paulo: Dublinense, 1939.

ROSA, João Guimarães. Primeiras estórias. Rio de Janeiro: Nova Fronteira, 1988.

ROSSET, Clément. O real e seu duplo: ensaio sobre a ilusão. Apres. e Trad. José Thomaz Brum. Porto Alegre: L\&PM, 1998.

TRIDAPALLI, Cezar. Mimosa pudica. In: RUFFATO, Luiz (Org.) 48 contos paranaenses. Curitiba: Biblioteca Pública do Paraná, 2014.

Revista Veja. Planta dormideira aprende e tem memória, afirma estudo. São Paulo, 2016. Disponível em:<https://veja.abril.com.br/ciencia/planta-dormideira-aprende-e-tem-memoria-afirma-estudo $\angle>$ Acesso em: 27 de janeiro de 2018.

TRIDAPALLI, Cezar. Curitiba, 2018. Disponível em:<http://cezartridapalli.com.br $>$ Acesso em: 28 de janeiro de 2018.

Recebido em: 18/04/2018. Aprovado em: 24/04/ 2018. 